\title{
Patient-controlled paravertebral analgesia for video-assisted thoracoscopic surgery lobectomy
}

This article was published in the following Dove Press journal: Local and Regional Anesthesia

Nguyen Truong Giang,' Nguyen Van Nam,' Nguyen Ngoc Trung,' Le Viet Anh,' Nguyen Manh Cuong, ${ }^{2} \mathrm{Ngo}$ Van Dinh, ${ }^{2}$ Dinh Cong Pho, ${ }^{2}$ Phillip Geiger, ${ }^{3}$ Nguyen Trung Kien ${ }^{2}$

'Department of Cardiothoracic Surgery, Military Hospital I03,Vietnam Military Medical University, Hanoi, Vietnam; ${ }^{2}$ Department of Anesthesia and Pain Medicine, Military Hospital 103, Vietnam Military Medical University, Hanoi, Vietnam; ${ }^{3}$ Department of Anesthesiology, Perioperative, and Pain Medicine, Naval Medical Center Portsmouth, Portsmouth, VA, USA

Video abstract

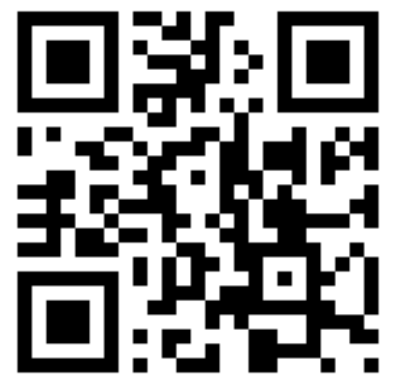

Point your SmartPhone at the code above. If you have a QR code reader the video abstract will appear. Or use: http://youtu.be/XEA3ECFmTrw

Correspondence: Nguyen Trung Kien Department of Anesthesia and Pain Medicine, Military Hospital 103, Vietnam Military Medical University, 26I Phung Hung road, Ha Dong District, Hanoi 100000, Vietnam

Tel +84979800922

Email drkien 103@gmail.com
Background: Paravertebral block has been proven to be an efficient method to provide postthoracotomy pain management. This study aimed to compare patient-controlled paravertebral analgesia (PCPA) and intravenous patient-controlled analgesia (IVPCA) in terms of analgesic efficiency, respiratory function, and adverse effects after video-assisted thoracoscopic surgery (VATS) lobectomy.

Patients and methods: The prospective randomized trial study was carried out on 60 patients who underwent VATS lobectomy (randomly allocated 30 patients in each group). In the PCPA group, an initial dose of $0.3 \mathrm{~mL} / \mathrm{kg}$ of $0.125 \%$ bupivacaine with fentanyl $2 \mu \mathrm{g} / \mathrm{mL}$ was administered, followed by a $3 \mathrm{~mL} / \mathrm{h}$ continuous infusion with patient-controlled analgesia (2 $\mathrm{mL}$ bolus, 10 -minute lockout interval, $25 \mathrm{~mL} / 4 \mathrm{~h}$ limit). In the IVPCA group with morphine 1 $\mathrm{mg} / \mathrm{mL}$ solution, an infusion device was programmed to deliver a $1.0 \mathrm{~mL}$ demand bolus with no basal infusion rate, with a 10-minute lockout interval and a maximum of $20 \mathrm{~mL} / 4 \mathrm{~h}$ period. Postoperative pain was assessed by visual analog scale at rest and on coughing. Arterial blood gas and spirometry were monitored and recorded for the first 3 postoperative days. Side effects to include were also recorded.

Results: The PCPA group had statistically significant lower pain scores $(P<0.0001)$ at rest at all times. Lower pain scores on coughing were statistically significant in PCPA group in the first 4 hours. Postoperative spirometry showed that both the groups had comparable recovery trajectories for their pulmonary function. Arterial blood gas analysis showed $\mathrm{pH}$ and $\mathrm{PaCO}_{2}$ were in a normal range in both the groups. The incidence of headache was higher in the IVPCA group (13.3\% vs $0 \%$; $P=0.038)$.

Conclusion: PCPA effectively managed pain after VATS lobectomy, with lower pain scores, similar respiratory function, and fewer side effects than standard IVPCA treatment.

Keywords: patient-controlled paravertebral analgesia, PCPA, intravenous patient controlled analgesia, IVPCA, video-assisted thoracoscopic surgery, VATS

\section{Introduction}

Compared to open thoracotomy, video-assisted thoracoscopic surgery (VATS) provides lower-risk interventions with smaller skin incisions and no rib retraction. This reduces damage to the thoracic wall, offering the potential for reduced postoperative respiratory dysfunction and pain. Acute pain after VATS maybe severe, with potential to evolve into significant chronic pain. ${ }^{1,2}$ Optimal pain management strategies after VATS is controversial. ${ }^{2}$ The use of paravertebral block (PVB) may be preferred over epidural analgesia, ${ }^{3-8}$ and some multimodal treatments have also shown excellent results..$^{9,10}$ 
A review of the literature from 2005 to 2015 suggests that thoracic PVB provides comparable analgesia to thoracic epidural analgesia (TEA) and, complemented with a pharmacological adjuvant, may represent a comparable alternative to TEA. ${ }^{11}$ Patient-controlled analgesia devices provide additional analgesia upon demand, and may be used to supplement paravertebral, epidural, or intravenous techniques. ${ }^{12,13}$

Because intravenous patient-controlled analgesia (IVPCA) is less invasive, costly, and labor intensive than patient-controlled paravertebral analgesia (PCPA), it would be preferable if it has a similar analgesic effect and safety characteristics. We conducted this study to compare the efficacy and side effect profiles of IVPCA and PCPA for the management of postoperative pain after VATS lobectomy.

\section{Patients and methods}

After obtaining approval from our institutional ethics committee (Military Hospital 103 Ethics Committee), 60 patients were enrolled in this randomized clinical trial. Patients classified as American Society of Anesthesiologist (ASA) physical status 1-3 underwent elective VATS lobectomy. ${ }^{1,2}$ Exclusion criteria included patient refusal to participate, age $<18$ years, ASA physical status $>3$, allergy to any of the study drugs, any contraindication to placement of PVB (severe coagulopathy, local infection, severe hypovolemia, untreated sepsis), preexisting chronic pain syndromes or chronic analgesic use, presence of acute herpes zoster, kyphoscoliosis, and psychiatric disease. All patients provided written informed consent, and the study was conducted in accordance with the Declaration of Helsinki.

Patients were thoroughly counseled about the procedures to be undertaken and the associated risks and benefits during a preoperative visit on the day before surgery. Each patient was instructed in how to evaluate his/her own pain using a visual analog scale (VAS) of 0-10 (0: no pain, 10: worst pain imaginable) and how to use a patient-controlled analgesia (PCA) device. Patients were directed to take $10 \mathrm{mg}$ oral diazepam the night before surgery and to fast for a period of at least 6 hours prior to surgery.

A computer-generated table was used to randomly assign the patients into experimental (PCPA) and control (IVPCA) groups of 30 .

After the application of standard monitors, including electrocardiography, noninvasive blood pressure (NIBP), and pulse oximetry, an intravenous saline infusion $(8 \mathrm{~mL} / \mathrm{kg} / \mathrm{h})$ was started. Pulse rate, peripheral arterial oxygen saturation $\left(\mathrm{SpO}_{2}\right)$, NIBP, and respiratory rate were noted. Equipment for general anesthesia and resuscitation were kept ready.
General anesthesia was induced with $2.0 \mathrm{mg} / \mathrm{kg}$ of propofol, $2.0 \mu \mathrm{g} / \mathrm{kg}$ of fentanyl, and $1.0 \mathrm{mg} / \mathrm{kg}$ of rocuronium. A double-lumen endotracheal tube was placed and appropriate position confirmed. Anesthesia was maintained with continuous infusion of propofol at the rate of $6-12 \mathrm{mg} / \mathrm{kg} / \mathrm{h}$, with $2 \mu \mathrm{g} / \mathrm{kg}$ of fentanyl and $0.15 \mathrm{mg} / \mathrm{kg}$ of rocuronium bloused every 30 minutes. After positioning patients in the lateral position, VATS was performed with one-lung ventilation.

In the PCPA group, paravertebral catheters (PVCs) were placed under sterile conditions upon completion of surgery. The upper edge of the spinous process of the thoracic vertebra (equidistant to the upper and lower intercostal space where ports had been placed) was recognized, and the needle insertion point was marked $2 \mathrm{~cm}$ lateral to the midline. Using a loss of resistance technique, the paravertebral space was entered by advancing a 22-G Tuohy epidural needle (B/ Braun, Melsungen, Germany) over the superior border of the transverse process. Catheter was passed through the needle, and the needle was removed, leaving 3-5 cm of the catheter in the paravertebral space. Advancement of the needle and insertion of the catheter were verified continuously by the surgeon using the camera (Figure 1).

A test dose of $3 \mathrm{~mL}$ of $1.5 \%$ lidocaine with 1:200,000 epinephrine was administered to detect inadvertent intravascular placement of the catheter, suggested by an increase in heart rate or mean arterial pressure of $>20 \%$ above the baseline value within 60 seconds. After confirmation of a negative test dose, an initial bolus of $0.3 \mathrm{~mL} / \mathrm{kg}$ of $0.125 \%$ bupivacaine with $2 \mu \mathrm{g} / \mathrm{mL}$ fentanyl was infused into the paravertebral space through the PVC (Figure 2).

After extubation, patients were encouraged to administer bolus doses of the same bupivacaine/fentanyl mixture via a PCA device (Perfusor Space; B/Braun). The device was programmed to provide a continuous infusion at $3 \mathrm{~mL} / \mathrm{h}$ and

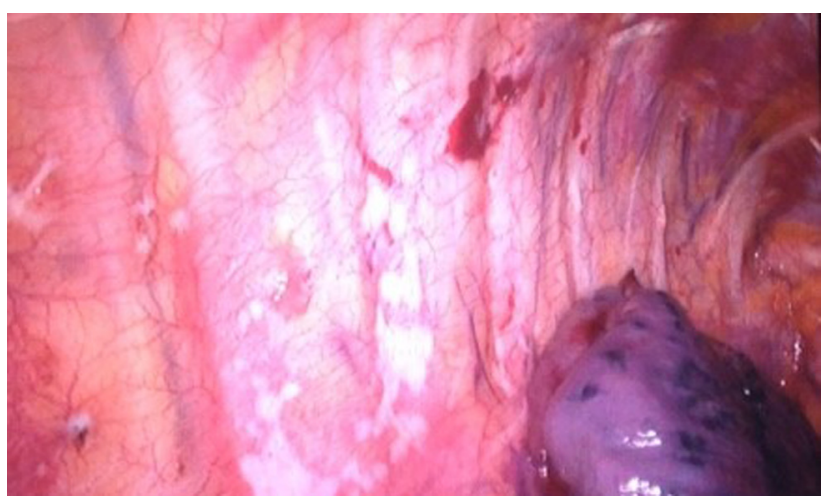

Figure I Access to paravertebral space. 
to permit a $2 \mathrm{~mL}$ of demand bolus with a 10-minute lockout interval, limited to $25 \mathrm{~mL}$ over 4 hours.

In the IVPCA group, patients received morphine $1 \mathrm{mg} /$ $\mathrm{mL}$ solution through PCA device. After extubation, we administered a $2 \mathrm{~mL}$ of bolus dose, supplemented with $1 \mathrm{~mL}$ every 3 minutes until VAS $<4$. At this time, the PCA pump was programmed to permit a $1 \mathrm{~mL}$ demand bolus with a 10-minute lockout interval, limited to $20 \mathrm{~mL}$ over 4 hours. No basal infusion was provided.

In both the groups, if a patient was uncomfortable and reported a VAS $>4$ after three consecutive demand boluses from the PCA, rescue analgesia of $0.5 \mu \mathrm{g} / \mathrm{kg}$ of IV fentanyl was provided. Chest drain with underwater seal drainages were removed when the patient condition was stable, radiological examination showed that the patient's lung got reinflated fully. And the volume of drainage was $<100 \mathrm{~mL} / 24 \mathrm{~h}$. After removing chest drainage tubes, pain management was remained with $500 \mathrm{mg}$ paracetamol oral route every 6 hours if VAS score over 4.

The following outcomes were assessed: 1) the effect of pain control on postoperative days (PODs), 2) respiratory

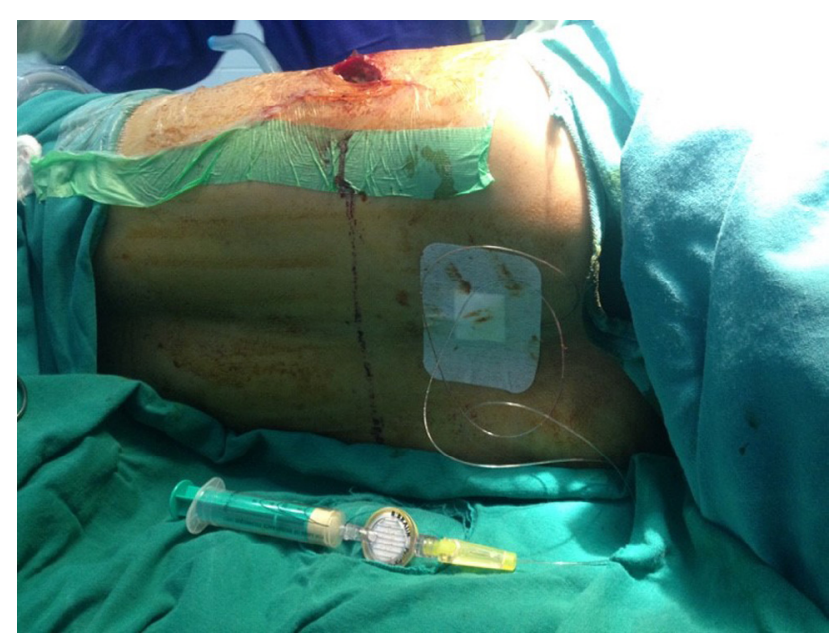

Figure 2 Paravertebral block. function (spirometry and arterial blood gas parameter), and 3) adverse events related to the analgesia technique, including respiratory depression (respiratory rate $<8$ breaths/ $\min$ ), urinary retention, nausea, vomiting, headache, and pruritus.

SPSS v21 package (IBM Corporation, Armonk, NY, USA) was used for statistical data analysis. The patient characteristics between the two groups were compared using a Student's $t$-test. Adjustment of data sets to a normal distribution was always verified for the applicability of parametric statistics (Kolmogorov-Smirnov test). Subsequently, the comparison of serial measurement (variables) was performed by two-way ANOVA test.

\section{Results}

Sixty patients with age from 32 to 72 years completed the study (30 in PCPA group, and 30 in IVPCA group). A successful PVB was achieved in all patients.

The demographic data of both the groups are shown in Table 1.

Postoperative pain scores at rest were compared at 0,2 , 4, 8, 16, 24, 36, 48, and 72 hours. Statistically significant lower pain scores were observed in PCPA group as compared to IVPCA group (Figure 3). Pain scores on coughing were compared at $0,2,4,8,16,24,36,48$, and 72 hours. Statistically significant lower pain scores were observed in PCPA group as compared to the IVPCA group for the first 4 hours (Figure 4). The need for rescue analgesia via rescue boluses of intravenous fentanyl (Table 2) was significantly lower in PCPA group (5 in PCPA group vs 44 in IVPCA group) $(P<0.001)$.

Compared to baseline values, postoperative $\mathrm{FVC}$ and FEV1 were reduced in both the groups at all time intervals. There were no significant differences between the groups (Table 3). Arterial blood gas analysis demonstrated comparable $\mathrm{pH}, \mathrm{PaO}_{2}$, and $\mathrm{PaCO}_{2}$ levels in both the groups throughout the study period (Table 4). Oxygenation was satisfactory

Table I Demographics comparison of study groups

\begin{tabular}{|l|l|l|}
\hline Characteristics & PCPA (n=30) & IVPCA (n=30) \\
\hline Age (years) & $50.9 \pm I I .3$ & $49.25 \pm 9.26$ \\
\hline Sex (M/F) & $23 / 7(76.6 \% / 23.4 \%)$ & $18 / 12(60 \% / 40 \%)$ \\
\hline Weight (kg) & $56.68 \pm 9.78$ & $52.13 \pm 6.2$ \\
\hline Height (cm) & $163.64 \pm 7.73$ & $162.18 \pm 7.82$ \\
\hline Operation time (min) & $175.36 \pm 42.39$ & $189.64 \pm 18.92$ \\
\hline Duration of chest tubes (days) & $5.46 \pm 1.35$ & $6.16 \pm 1.26$ \\
\hline Postoperative hospital stay (days) & $13.43 \pm 6.96$ & $15.06 \pm 8.27$ \\
\hline
\end{tabular}

Notes: Results are presented as mean $\pm \mathrm{SD}$, or as \% of group total.

Abbreviations: IVPCA, intravenous patient-controlled analgesia; M/F, male/female; PCPA, patient-controlled paravertebral analgesia. 


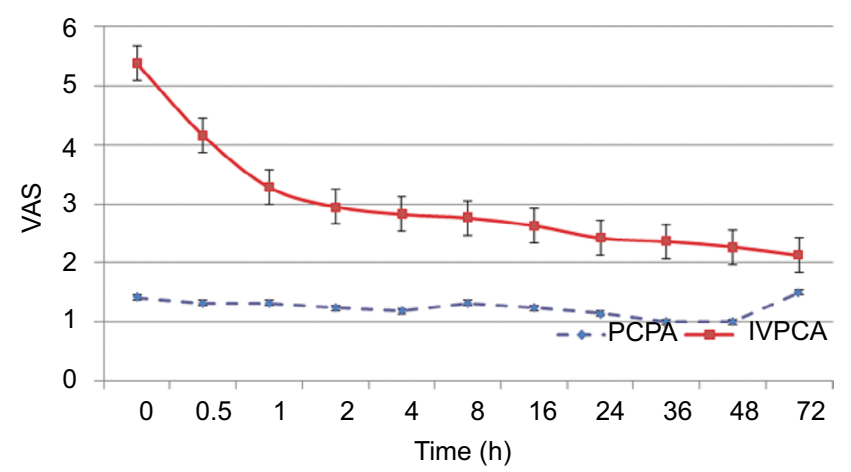

Figure 3 VAS at rest.

Abbreviations: PCPA, patient-controlled paravertebral analgesia; IVPCA, intravenous patient-controlled analgesia; VAS, visual analog scale.

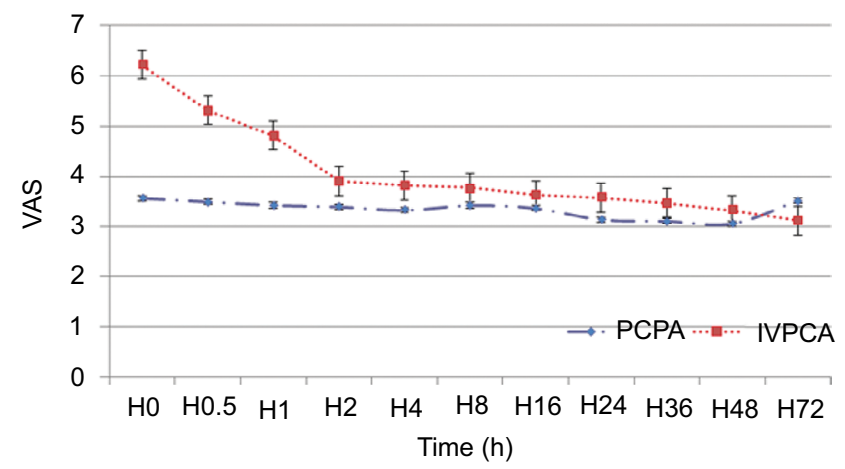

Figure 4 VAS on coughing.

Abbreviations: PCPA, patient-controlled paravertebral analgesia; IVPCA, intravenous patient-controlled analgesia; VAS, visual analog scale.

Table 2 Characteristics of analgesia procedure

\begin{tabular}{|l|l|l|l|}
\hline Characteristics & PCPA & IVPCA & P-value \\
\hline $\begin{array}{l}\text { The number dermatome } \\
\text { inhibition I/2/3/4 }\end{array}$ & $\mathrm{I} / 2 / 15 / 12$ & & \\
\hline Rescue analgesia & 5 & 44 & $<0.00 \mathrm{I}$ \\
\hline Bupivacaine consumption $(\mathrm{mg})$ & $304.7 \pm 8.3$ & & \\
\hline Morphine consumption $(\mathrm{mg})$ & & $54.62 \pm 5.59$ & \\
\hline
\end{tabular}

Abbreviations: IVPCA, intravenous patient-controlled analgesia; PCPA, patientcontrolled paravertebral analgesia.
$\left(\mathrm{PaO}_{2}>90 \mathrm{mmHg}\right)$ in all patients during the study period in PCPA group. No patients in either group suffered respiratory depression (Table 5).

The incidence of headache was higher in the IVPCA group (occur only at IVPCA group [13.3\%]). Nausea and vomiting were experienced by $16.6 \%$ of patients in IVPCA group and $13.3 \%$ in PCPA group. Pruritis was experienced by $3.3 \%$ of patients in IVPCA group vs no patients in PCEA group (Table 5).

\section{Discussion}

We investigated whether postoperative pain management with PCPA has a superior benefits and risk profile compared to IVPCA in patients undergoing VATS. Patients with PCPA using fentanyl and bupivacaine as compared to IVPCA using morphine, following VATS lobectomy, had superior analgesia both at rest and during coughing, with a lower incidence of side effects.

Since it was first described in 1992, ${ }^{14}$ lobectomy via VATS has been increasingly performed as an alternative to resection by thoracotomy due to the minimally invasive nature of the procedure and its many advantages. ${ }^{15}$ We demonstrated that placement of a PVC under video guidance is a simple and safe technique, as previously shown by Karmakar. ${ }^{16}$ In our study, the success rate for PVC placement was $100 \%$. The failure rate varies between $6.8 \%$ and $10 \%$ without the use of a support device technique. ${ }^{17,18}$

Thoracic PVB provides effective post-thoracotomy analgesia, and the optimal way to deliver drugs into the paravertebral space is still being investigated. ${ }^{19}$ Single-shot preoperative PVB may represent an advantage over multiple-injection PVB in patients undergoing VATS. ${ }^{20,21}$ Results from a research of Català et al suggest that continuous thoracic paravertebral infusion provides better pain control than a bolus regimen. ${ }^{22}$

The most remarkable result to emerge from the data is that VAS scores of PCPA group at rest and on coughing were

Table 3 FVC and FEVI parameters

\begin{tabular}{|l|l|l|l|l|l|l|}
\hline \multirow{2}{*}{$\begin{array}{l}\text { Parameters } \\
\text { (time) }\end{array}$} & \multicolumn{2}{|l|}{ FVC (L) } & \multicolumn{2}{l|}{ FEVI (L) } \\
\cline { 2 - 7 } & PCPA (n=30) & IVPCA (n=30) & P-value & PCPA (n=30) & \multicolumn{1}{l|}{ IVPCA (n=30) } & P-value \\
\hline Pre-operation & $2.78 \pm 0.64$ & $2.71 \pm 0.51$ & 0.6412 & $2.12 \pm 0.66$ & $2.07 \pm 0.52$ & 0.7456 \\
\hline POD I & $1.27 \pm 0.44$ & $1.22 \pm 0.16$ & 0.5609 & $0.88 \pm 0.31$ & $0.87 \pm 0.14$ & 0.8726 \\
\hline POD 2 & $1.41 \pm 0.37$ & $1.37 \pm 0.24$ & 0.6212 & $1.05 \pm 0.27$ & $1.01 \pm 0.17$ & 0.4950 \\
\hline POD 3 & $1.68 \pm 0.54$ & $1.65 \pm 0.35$ & 0.7994 & $1.29 \pm 0.47$ & $1.25 \pm 0.25$ & 0.6822 \\
\hline
\end{tabular}

Note: Results are presented as mean \pm SD.

Abbreviations: PCPA, patient-controlled paravertebral analgesia; IVPCA, intravenous patient-controlled analgesia; POD, postoperative day. 
Table 4 Arterial blood gas analysis

\begin{tabular}{|l|l|l|l|l|l|l|l|l|}
\hline \multirow{2}{*}{ Characteristics } & \multicolumn{3}{l|}{ Before operation } & \multicolumn{2}{l|}{ POD I } & \multicolumn{2}{l|}{ POD 2 } & \multicolumn{2}{l|}{ POD 3 } \\
\cline { 2 - 9 } & PVB & IVPCA & PVB & IVPCA & PVB & IVPCA & PVB & IVPCA \\
\hline $\mathrm{PaCO}_{2}(\mathrm{mmHg})$ & $38.04 \pm 5.27$ & $37.32 \pm 2.3 \mathrm{I}$ & $38.72 \pm 8.68$ & $39.53 \pm 3.27$ & $38.63 \pm 3.17$ & $39.45 \pm 2.45$ & $36.86 \pm 4.66$ & $42.66 \pm 2.45$ \\
\hline $\mathrm{pH}$ & $7.38 \pm 0.04$ & $7.428 \pm 0.0 \mathrm{I}$ & $7.36 \pm 0.05$ & $7.388 \pm 0.03$ & $7.40 \pm 0.04$ & $7.337 \pm 0.01$ & $7.43 \pm 0.02$ & $7.345 \pm 0.01$ \\
\hline
\end{tabular}

Note: Results are presented as mean \pm SD.

Abbreviations: PVB, paravertebral block; IVPCA, intravenous patient-controlled analgesia; POD, postoperative day.

Table 5 Side effects and complications

\begin{tabular}{|l|l|l|l|}
\hline Symptoms/signs & PVB, $\mathbf{n = 3 0}$ & IVPCA, $\mathbf{n}=\mathbf{3 0}$ & P-value \\
\hline Respiratory depression & 0 & 0 & \\
\hline Nausea and vomiting & $4(\mathrm{I3.3} \%)$ & $5(\mathrm{I} 6.6 \%)$ & 0.718 \\
\hline Pruritus & 0 & $\mathrm{I}(3.3 \%)$ & 0.313 \\
\hline Headache $^{\mathrm{a}}$ & 0 & $4(\mathrm{I3.3} \%)$ & 0.038 \\
\hline Urinary retention & 0 & 0 & \\
\hline
\end{tabular}

Notes: Results are presented as number ofpatients who experienced the side effect. alncidence of headachewas statistically significantly higher in the IVPCA group. Abbreviations: PVB, paravertebral block; IVPCA, intravenous patient-controlled analgesia.

lower than the IVPCA group. VAS scores on coughing group were variable between $\mathrm{H} 48$ and $\mathrm{H} 72$. This finding may be explained by after chest tube removal combined with the discontinuation of infusions (H72). In post-thoracic surgery analgesia, it is likely that complete pain control may not be achievable with a single agent or technique and that a balanced analgesic regime may be more appropriate. Some authors used IVPCA for post-thoracotomy and provided adequate analgesia effects with few side effects..$^{23,24}$ Garutti et al showed that the use of PVCs provides excellent results in post-thoracotomy pain control. ${ }^{25}$ Several authors have demonstrated that a thoracic PVB before VATS provides excellent pain relief with few side effects during the first postoperative hours. ${ }^{20,26,27}$ In our study, PVCs with continuous infusions and patient-controlled boluses provide pain relief from completion of surgery until removal 3 days after surgery.

The principal benefit of PCA devices is individually titrated dosing to provide adequate analgesia, while reducing side effects and complications rate that might be caused by unnecessarily higher doses. The number of dermatomes affected by PVB has been studied by Cheema et al. ${ }^{28}$ Greater volumes of local anesthetic will extend blockade to more dermatomes and extend the analgesic effect. However, greater volumes carry a risk of reaching the epidural space through the lateral foramen, exposing patients to additional risks, including undesired vertical or contralateral spread.

Our results showed that a $0.3 \mathrm{~mL} / \mathrm{kg}$ bolus of $0.125 \%$ bupivacaine with $2 \mu \mathrm{g} / \mathrm{mL}$ fentanyl achieved a satisfactory analgesic effect, with extensions to three dermatomes in 50\% of patients, and four dermatomes in $40 \%$ of patients. The factors affecting the spread of bupivacaine in the thoracic paravertebral space have been studied by Cheema et al. ${ }^{28}$ The more the number of dermatome inhibition we had, the more analgesia efficacy it increases. But if drugs were too much, it will enter epidural space through lateral foramen and expose patients to additional risks. Our results showed that it achieved analgesia efficacy. Five patients required fentanyl injection to provide rescue analgesia in PCPA group; however, in these cases, the chest tube had been displaced by transport or sudden movement. The frequency of rescue analgesia was significantly lower in PCPA group, suggesting that PCPA provides more reliable and consistent analgesia than IVPCA.

Both open thoracotomy and VATS have the potential to severely compromise respiratory mechanics and gas exchange; in this respect, they are among the most damaging surgical insults a patient may receive. ${ }^{29,30}$ Post-thoracotomy pain discourages deep inspiration, and poor analgesia after thoracotomy can lead to impaired coughing, reducing the patient's ability to clear secretions, risking respiratory failure. Elsayed et al found a correlation between surrogate measures of pulmonary function and important outcome measures and that PVC use is associated with a shorter hospital stay (6 vs 7 days; $P=0.008) .{ }^{31}$ We assessed spirometry results and arterial blood gas analysis to evaluate pulmonary function.

In both the groups, FVC and FEV1 had decreased significantly on POD 1 compared to baseline values. Both the groups recovered at comparable rates between POD 1 and POD 3. Improvement in spirometry over time after thoracic surgery is well described by other authors. ${ }^{4,32,33}$ Our results suggest that the benefits of IVPCA in terms of restoration of pulmonary function were equal to those of PCPA in patients undergoing VATS. Assessment of the effect of pain relief on spirometry is subject to some confounding factors, notably the possibility that the surgery itself might have altered lung volumes (eg, lobe resection, removal of mass effect). Other studies suggest that decreases in FVC and FEV1 to as little as 59\%-64\% of predicted values can be expected on POD $1,{ }^{34}$ with recovery 
to $85 \%-90 \%$ by POD $7 .{ }^{35}$ Our patients demonstrated values of $41 \%-45 \%$ at POD 1 and showed improvement until POD 3. Because we did not measure spirometry after POD 3, further direct comparison with the above studies was not possible. The reason why we did not check the FVC and FEV1 after POD 3 is that we assumed that if there was a difference in pulmonary function recovery between the groups, it would appear in the acute postoperative period.

Arterial blood gas analysis showed that there were no significant differences between the two groups. $\mathrm{pH}$ and $\mathrm{PaCO}_{2}$ were in a normal range in both the groups. We did not show $\mathrm{PaO}_{2}$, and it can be explained by using oxygen support after surgery. Oxygen support depends on patient status. If we did not know how many patients get supplemental $\mathrm{O}_{2}$, then the average $\mathrm{PaO}_{2}$ measurements really do not mean anything. This analysis provides general looks, and it is about the analgesia effect on respiratory function, side effects, and complications. Clinicians can use it to make some changes in treatment strategies. Further study should be done to evaluate the variety of arterial blood gas after VATS procedure.

The complication rate was low. In our study, although there were slightly higher tendencies for nausea and vomiting in the IVPCA group, these differences were not significant. Other studies haves shown the same results. ${ }^{36-38}$ Headaches were only noted to occur in the IVPCA group.

\section{Conclusion}

PCPA is an effective technique to manage pain after VATS. The resulting analgesia is superior to the IVPCA regimen we tested. No patient in either group suffered significant complications, and recovery of postoperative respiratory function was similar between the groups. PCPA may be associated with fewer side effects than IVPCA.

One limitation of our study is that we have not followed up patients after their discharge from the hospital. Our findings are limited to the acute postoperative period.

\section{Author contributions}

All authors contributed to data analysis, drafting and revising the article, gave final approval of the version to be published, and agree to be accountable for all aspects of the work. Particularly, DCP made substantial contributions to the conception and design of this manuscript, acquisition of data, interpretation of data, and drafting the article. NTG, NVN, NNT, and LVA contributed to collect data. NMC and NVD had a contribution in analyzing data. NTK prepared and revised this manuscript and is the corresponding author. PG had great contribution to edit manuscript.

\section{Disclosure}

The authors report no conflicts of interest in this work.

\section{References}

1. Richardson J, Cheema S. Thoracic paravertebral nerve block. $\mathrm{Br} J$ Anaesth. 2006;96(4):537.

2. Gerner P. Postthoracotomy pain management problems. Anesthesiol Clin. 2008;26(2):355-367.

3. Marret E, Bazelly B, Taylor G, et al. Paravertebral block with ropivacaine $0.5 \%$ versus systemic analgesia for pain relief after thoracotomy. Ann Thorac Surg. 2005;79(6):2109-2113.

4. Gulbahar G, Kocer B, Muratli SN, et al. A comparison of epidural and paravertebral catheterisation techniques in post-thoracotomy pain management. Eur J Cardiothorac Surg. 2010;37(2):467-472.

5. Scarci M, Joshi A, Attia R. In patients undergoing thoracic surgery is paravertebral block as effective as epidural analgesia for pain management? Interact Cardiovasc Thorac Surg. 2010;10(1):92-96.

6. Júnior AP, Erdmann TR, Santos TV, et al. Comparison between continuous thoracic epidural and paravertebral blocks for postoperative analgesia in patients undergoing thoracotomy: systematic review. Braz J Anesthesiol. 2013;63(5):433-442.

7. Baidya DK, Khanna P, Maitra S. Analgesic efficacy and safety of thoracic paravertebral and epidural analgesia for thoracic surgery: a systematic review and meta-analysis. Interact Cardiovasc Thorac Surg. 2014; 18(5):626-635.

8. Ding X, Jin S, Niu X, Ren H, Fu S, Li Q. A comparison of the analgesia efficacy and side effects of paravertebral compared with epidural blockade for thoracotomy: an updated meta-analysis. PLoS One. 2014;9(5):e96233.

9. Fibla JJ, Molins L, Mier JM, Sierra A, Vidal G. Comparative analysis of analgesic quality in the postoperative of thoracotomy: paravertebral block with bupivacaine $0.5 \%$ vs ropivacaine $0.2 \%$. Eur J Cardiothorac Surg. 2008;33(3):430-434.

10. Fibla JJ, Molins L, Mier JM, Sierra A, Vidal G. A prospective study of analgesic quality after a thoracotomy: paravertebral block with ropivacaine before and after rib spreading. Eur J Cardiothorac Surg. 2009;36(5):901-905.

11. Rodriguez-Aldrete D, Candiotti KA, Janakiraman R, Rodriguez-Blanco YF. Trends and new evidence in the management of acute and chronic post-thoracotomy pain-an overview of the literature from 2005 to 2015. J Cardiothorac Vasc Anesth. 2016;30(3):762-772.

12. Sentürk M, Özcan PE, Talu GK, et al. The effects of three different analgesia techniques on long-term postthoracotomy pain. Anesth Analg. 2002;94(1):11-15.

13. Kaplowitz J, Papadakos PJ. Acute pain management for video-assisted thoracoscopic surgery: an update. J Cardiothorac Vasc Anesth. 2012;26(2):312-321.

14. Roviaro G, Rebuffat C, Varoli F, Vergani C, Mariani C, Maciocco M. Videoendoscopic pulmonary lobectomy for cancer. Surg Laparosc Endosc. 1992;2(3):244-247.

15. Whitson BA, Groth SS, Duval SJ, Swanson SJ, Maddaus MA. Surgery for early-stage non-small cell lung cancer: a systematic review of the video-assisted thoracoscopic surgery versus thoracotomy approaches to lobectomy. Ann Thorac Surg. 2008;86(6):2008-2018.

16. Karmakar MK. Thoracic paravertebral block. Anesthesiology. 2001;95(3):771-780.

17. Coveney E, Weltz CR, Greengrass R, et al. Use of paravertebral block anesthesia in the surgical management of breast cancer: experience in 156 cases. Ann Surg. 1998;227(4):496-501.

18. Naja Z, Lönnqvist PA. Somatic paravertebral nerve blockade incidence of failed block and complications. Anaesthesia. 2001;56(12): 1181-1201.

19. Asida SM, Youssef IA, Mohamad AK, Abdelrazik AN. Post-thoracotomy pain relief: thoracic paravertebral block compared with systemic opioids. Egypt J Anaesth. 2012;28(1):55-60. 
20. Vogt A, Stieger DS, Theurillat C, Curatolo M. Single-injection thoracic paravertebral block for postoperative pain treatment after thoracoscopic surgery. Br J Anaesth. 2005;95(6):816-821.

21. Kaya FN, Turker G, Mogol EB, Bayraktar S. Thoracic paravertebral block for video-assisted thoracoscopic surgery: single injection versus multiple injections. J Cardiothorac Vasc Anesth. 2012;26(1): 90-94.

22. Català E, Casas JI, Unzueta MC, Diaz X, Aliaga L, Villar Landeira JM. Continuous infusion is superior to bolus doses with thoracic paravertebral blocks after thoracotomies. J Cardiothorac Vasc Anesth. 1996;10(5):586-588

23. Kim JA, Kim TH, Yang M, et al. Is intravenous patient controlled analgesia enough for pain control in patients who underwent thoracoscopy? J Korean Med Sci. 2009;24(5):930-935.

24. Wang X, Wang K, Wang B, et al. Effect of oxycodone combined with dexmedetomidine for intravenous patient-controlled analgesia after video-assisted thoracoscopic lobectomy. J Cardiothorac Vasc Anesth. 2016;30(4):1015-1021.

25. Garutti I, González-Aragoneses F, Biencinto MT, et al. Thoracic paravertebral block after thoracotomy: comparison of three different approaches. Eur J Cardiothorac Surg. 2009;35(5):829-832.

26. Kaya FN, Turker G, Basagan-Mogol E, Goren S, Bayram S, Gebitekin C. Preoperative multiple-injection thoracic paravertebral blocks reduce postoperative pain and analgesic requirements after video-assisted thoracic surgery. J Cardiothorac Vasc Anesth. 2006;20(5):639-643.

27. Hill SE, Keller RA, Stafford-Smith M, et al. Efficacy of single-dose, multilevel paravertebral nerve blockade for analgesia after thoracoscopic procedures. Anesthesiology. 2006;104(5):1047-1053.

28. Cheema S, Richardson J, McGurgan P. Factors affecting the spread of bupivacaine in the adult thoracic paravertebral space. Anaesthesia. 2003;58(7):684-687.
29. Warner DO. Preventing postoperative pulmonary complications: the role of the anesthesiologist. Anesthesiology. 2000;92(5):1467-1472.

30. Toori KU, Khan JS, Nomani Z, Hussain SW. A prospective study of factors predicting postoperative pulmonary complications (PPC) in patients undergoing non-cardiothoracic surgery under general anaesthsia in a developing country. Anaesth Pain \& Intensive Care . 2012;16(3):252-256.

31. Elsayed H, McKevith J, McShane J, Scawn N. Thoracic epidural or paravertebral catheter for analgesia after lung resection: is the outcome different? J Cardiothorac Vasc Anesth. 2012;26(1):78-82.

32. Amr YM, Yousef AA, Alzeftawy AE, Messbah WI, Saber AM. Effect of preincisional epidural fentanyl and bupivacaine on postthoracotomy pain and pulmonary function. Ann Thorac Surg. 2010;89(2):381-385.

33. Davies RG, Myles PS, Graham JM. A comparison of the analgesic efficacy and side-effects of paravertebral vs epidural blockade for thoracotomy--a systematic review and meta-analysis of randomized trials. Br J Anaesth. 2006;96(4):418-426.

34. Furrer M, Rechsteiner R, Eigenmann V, Signer C, Althaus U, Ris HB. Thoracotomy and thoracoscopy: postoperative pulmonary function, pain and chest wall complaints. Eur J Cardiothorac Surg. 1997;12(1):82-87.

35. Nakata M, Saeki H, Yokoyama N, Kurita A, Takiyama W, Takashima S Pulmonary function after lobectomy: video-assisted thoracic surgery versus thoracotomy. Ann Thorac Surg. 2000;70(3):938-941.

36. Ladak SS, Katznelson R, Muscat M, Sawhney M, Beattie WS, O’Leary $\mathrm{G}$. Incidence of urinary retention in patients with thoracic patientcontrolled epidural analgesia (TPCEA) undergoing thoracotomy. Pain Manag Nurs. 2009;10(2):94-98.

37. Duarte LT, Fernandes MC, Costa VV, Saraiva RA. [The incidence of postoperative respiratory depression in patients undergoing intravenous or epidural analgesia with opioids]. Rev Bras Anestesiol. 2009;59(4):409-420.

38. Macintyre PE. Safety and efficacy of patient-controlled analgesia. $B r$ J Anaesth. 2001;87(1):36-46.
Local and Regional Anesthesia

\section{Publish your work in this journal}

Local and Regional Anesthesia is an international, peer-reviewed, open access journal publishing on the development, pharmacology, delivery and targeting and clinical use of local and regional anesthetics and analgesics. The journal is included in PubMed, and welcomes submitted papers covering original research, basic science, clinical studies,

\section{Dovepress}

reviews and evaluations, guidelines, expert opinion and commentary, case reports and extended reports. The manuscript management system is completely online and includes a very quick and fair peer-review system, which is all easy to use. Visit http://www.dovepress.com/ testimonials.php to read real quotes from published authors. 